\title{
Empirical Modeling and Multi-Response Optimization of Laser Transmission Welding of Polycarbonate to ABS
}

\author{
Bappa Acherjee - Arunanshu S. Kuar • \\ Souren Mitra • Dipten Misra
}

Accepted: 17 February 2015 / Published online: 7 March 2015

(C) Springer New York 2015

\begin{abstract}
In present research, laser transmission welding of polycarbonate to ABS has been investigated through empirical modeling. The effect of laser power, welding speed, stand-off distance and clamp pressure on weld strength and track width is investigated using the empirical models developed by response surface methodology. Laser power and stand-off distance have shown the dominant effect on the weld strength and track width, respectively. Numerical and graphical optimization schemes are used to find out the optimal welding conditions which satisfy multiple objectives, simultaneously. The optimal welding parameter combinations are presented in favors of high welding strength and low track width. Overlay graphs are plotted by superimposing the contours for the various response surfaces. Optimal solutions are found that would improve the weld quality within the selected range of process parameters.
\end{abstract}

Keywords Laser transmission welding · Dissimilar plastics $\cdot$ Modeling and optimization

\section{Introduction}

Laser transmission welding of dissimilar polymers is at the evolving stage for wide industrial applications. Polycarbonate (PC) is a clear, colorless polymer, having high

Electronic supplementary material The online version of this article (doi:10.1007/s40516-015-0009-0) contains supplementary material, which is available to authorized users.

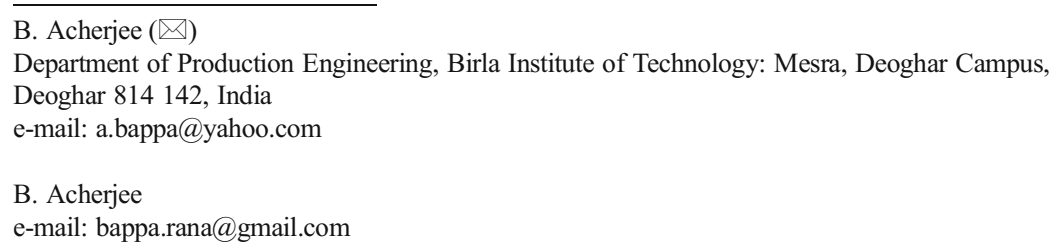

A. S. Kuar • S. Mitra

Department of Production Engineering, Jadavpur University, Kolkata 700 032, India

D. Misra

School of Laser Science \& Engineering, Jadavpur University, Kolkata 700 032, India 
strength, toughness and heat resistance. PC is extensively used in engineering and optical applications. PC is chemically compatible with ABS (acrylonitrile butadiene styrene), a copolymer, which exhibits a balanced combination of mechanical toughness, good dimensional stability, and chemical resistance. They have been successfully laser welded and adapted into industrial production. A number of applications of laser welding of PC to ABS are there in automotive industries such as front and rear lights assemblies, dash board components, flood lights, etc. Laser welding is successfully applied to contour welding of mobile phone cover, display and cabinets, selves etc. [1]. However, no such comprehensive research work has been reported on laser welding of PC to ABS by considering multiple quality criteria, which is of prime importance to enhance the product quality. Therefore, an extensive research work is much needed to generate technology guidance for laser welding of such a useful material combination. This would aid to the selection of optimum process parameters for achieving the desired product quality.

Laser welding technique often provides solutions where conventional plastic joining techniques have failed or required to be improved upon. This is a noncontact, non-contaminant, flexible joining process, which produces optically and qualitatively high-grade joints. In laser transmission welding of thermoplastics, the laser beam penetrates the upper, transparent joining part and is completely absorbed by the lower, laser absorbing part. The radiation is converted into localized heat and melting takes place. The heat required to melt the transparent joining part is received from the thermal conduction of the absorbing part. Strong welding of both parts occurs under external compression and the internal joining pressure, arising from local warming and expansion [2].

Presence of reinforcements, mineral fillers, impact modifiers, and some heat stabilizers in polymer matrix affect the optical and mechanical properties of the materials and thereby the mechanical performance of the weld [1-4]. Baylis et al. [2] investigated the effect of laser welding parameters on the laser transmission weld quality, characterized by weld width and strength for lap welded thermoplastic elastomers to polypropylene. Haberstroh et al. [4] showed the influence of carbon black content on the formation of the weld seam when joining thermoplastics in micro-technology applications. A diode laser beam was applied to overlapped polycarbonate samples using masked welding technique. Haberstroh and Luetzeler [5] carried out an experimental study on laser welding of polymer using proprietary box geometry with three dimensional weld line. At favorable process conditions low leakage and high burst pressure is achieved for polyamide and polyacetal. Douglass and Wu [6] considered laser power, welding speed and clamping pressure as input parameters and determined their effect on the lap shear strength of lap welded soft and hard polyolefin elastomer to thermoplastic polyolefin. Grewell et al. [7] studied the relationship between optical properties and optimized processing parameters of laser transmission welding. Various commercially available nylon 6 grade plastics are used for welding at simultaneous welding mode using a high power diode laser system. Prabhakaran et al. [8] studied the effect of contour laser welding parameters on meltdown and weld strength for T-joint welded $30 \%$ glass reinforced Nylon 6. Wehner et al. [9] applied diode laser transmission welding in the manufacturing of micro-fluidic devices. Ilie et al. [10] investigated the laser beam weldability of ABS plates by combining both experimental and theoretical aspects. The qualitative analysis of the test plates showed that for the laser power 14-17 W, a high value of the failure force was recorded indicating 
a good quality of the weld joint in the domain. Ghorbel at al. [11] investigated the influence of process parameters viz. laser power and welding speed on the geometry and the microstructure of the weld zone using finite element analysis. Speka et al. [12] acquired temperature profiles during laser transmission welding by infrared thermography and also compared it with numerical solutions during heating and cooling phase. The work materials used for this study were a semitransparent PMMA and an ABS-PC alloy, opaque in near-infrared spectrum. Amanat et al. [13] assessed the efficiency of laser transmission welding of PEEK using Clearweld ${ }^{\circledR}$ as the infrared absorbing medium. Acherjee et al. [14] presented a study on the effects of laser transmission contour welding parameters on the weld quality of acrylics. The results of analysis of variance confirmed that the power and welding speed have the most significant effects on the welding. Acherjee et al. [15] developed a statistical model to predict the weld quality and to optimize the process parameters for laser transmission welding of acrylic to ABS. Vidal et al. designed and developed a tailored laser system [16], to perform laser transmission welding of natural ABS to opaque ABS filled with carbon-nanotubes (CNT), and analyzed the effect of process parameters and CNTs concentrations on weld formation and mechanical properties of the weld $[16,17]$. The key process parameters for laser transmission welding are: laser power, welding speed, stand-off distance and clamping pressure [8], which control the temperature field inside the weld seam, and hence the weld quality. For a good weld quality, the combination of the process parameters should be correctly selected. Response Surface Methodology is widely used for developing empirical models to predict the weld bead geometry and mechanical properties in welding processes [18-20]. These empirical models are very useful not only for predicting the weld quality, but also for selecting the optimum process parameters for achieving the desired quality and process optimization [18].

In the present research, a comprehensive experimental investigation and multi-objective optimization of laser transmission welding of PC to ABS has been carried out, in continuation to authors' previous investigation [21]. Response surface methodology (RSM) is employed to develop mathematical relationships between the welding process parameters and the output variables, namely, weld strength and track width. The developed empirical model is tested by analysis-of-variance (ANOVA) method to check its adequacy. The effects of process parameters on weld qualities are discussed based on the developed empirical model. Optimization module of Design Expert ${ }^{\circledR}$ software is employed to determine the optimal process parameters. The software uses inbuilt numerical and graphical optimization techniques to uncover the desirable response values in the factor space to choose optimum welding parameters combination.

\section{Research Methods}

\section{Response Surface Methodology}

Response Surface Methodology is a collection of statistical and mathematical techniques useful for developing, improving, and optimizing processes [22]. The most extensive applications of RSM are in the particular situations where several input variables potentially influence some performance measure or 
quality characteristic of the process. If all variables are assumed to be measurable, the response surface can be expressed as follows:

$$
y=f\left(x_{1}, x_{2}, \ldots, x_{k}\right)
$$

where $y$ is the response of the system, and $x_{i}$ the variables of action called factors.

In the practical application of RSM it is necessary to develop an approximating model for the true response surface. The approximating model is based on observed data from the process or system and is an empirical model. Multiple regression analysis is a collection of statistical techniques useful for building the types of empirical models required in RSM. Usually a second order polynomial equation is used in RSM:

$$
y=\beta_{0}+\sum_{i=1}^{k} \beta_{i} x_{i}+\sum_{i=1}^{k} \beta_{i i} x_{i}^{2}+\sum_{i=1}^{k-1} \sum_{j=2}^{k} \beta_{i j} x_{i} x_{j}
$$

where, parameters $\beta_{i, j=0,1, \ldots, k}$ are called the regression coefficients.

\section{Desirability Function Analysis}

The desirability function analysis method is the technique for combining multiple responses into a dimensionless measure of performance called the composite desirability function. The general approach of desirability function is to transfer each response $y_{i}$ into an unitless desirability function $d_{i}$ bounded by $0 \leq d_{i} \leq 1$, where, the desirable ranges are from zero to one, as least to most desirable, respectively [22].

For goal of maximum, the desirability will be defined by:

$$
d_{i}=\left\{\begin{array}{cc}
\left(\frac{y_{i}-L_{i}}{H_{i}-L_{i}}\right)^{w t_{i}} ; \text { if response }\left(y_{i}\right) \leq \text { low value }\left(L_{i}\right) \\
1 \quad \text { as response }\left(y_{i}\right) \text { varies from low }\left(L_{i}\right) \text { to high }\left(H_{i}\right) \\
; \text { if response }\left(y_{i}\right) \geq \operatorname{high} \text { value }\left(H_{i}\right)
\end{array}\right.
$$

For goal of minimum, the desirability will be defined by:

$$
d_{i}=\left\{\begin{array}{cc} 
& ; \text { if response }\left(y_{i}\right) \leq \text { low value }\left(L_{i}\right) \\
\left(\frac{H_{i}-y_{i}}{H_{i}-L_{i}}\right)^{w t_{i}} ; \text { as response }\left(y_{i}\right) \text { varies from low }\left(L_{i}\right) \text { to high }\left(H_{i}\right) & ; \text { if response }\left(y_{i}\right) \geq \operatorname{high} \text { value }\left(H_{i}\right)
\end{array}\right.
$$

A weight (wt) can be assigned to a goal to emphasize the particular desirability function. Weights can be ranged between 0.1 and 10. A weight greater than 1 gives more emphasis to the goal, while weights less than 1 give less emphasis.

The simultaneous objective function, $D$ is a geometric mean of all transformed responses:

$$
D=\left(d_{1}^{r_{1}} \times d_{1}^{r_{2}} \times \ldots \ldots \times d_{1}^{r_{n}}\right) \overline{\frac{1}{\sum r_{i}}}=\left(\prod_{i=1}^{n} d_{i}^{r_{i}}\right) \overline{\sum r_{i}}
$$


where, $n$ is the number of responses in the measure. Each response can be assigned an importance, relative to the other responses. Importance $\left(r_{i}\right)$ values varies from 1 , the least important, to five, the most important.

\section{Experimental Work}

\section{Experimental Design}

The following independently controllable process parameters are identified to carry out the experiments: laser power, welding speed, stand-off-distance and clamp pressure. The ranges of the process parameters are selected on the basis of trial experiments conducted by using one factor at a time approach. The working range is decided by inspecting the weld seam for a smooth appearance and the absence of any visible defects. The selected process parameters and their limits, units and notations are given in Table 1.

The selected design matrix is a four factors five levels central composite rotatable design with full replications consisting of 30 sets of coded conditions and comprising a full replication of $2^{4}(=16)$ factorial design plus six center points and eight star points. All welding variables at the intermediate $(0)$ level constitute the center points while the combination of each of the welding variables at either its lowest value $(-2)$ or its highest value $(+2)$ with the other three variables at the intermediate levels constitute the star points. Thus, the 30 experimental runs allowed the estimation of the linear, quadratic and two-way interactive effects of the process parameters on the response parameters. Statistical software Design Expert ${ }^{\circledR}$ is used to code the variables and to establish the design matrix. RSM is applied to the experimental data using the same software to obtain the regression equations and to generate the statistical and response plots.

\section{Materials and Process}

Makrolon ${ }^{\circledR} 2605$ polycarbonate granules from Bayer Material Science and Terluran ${ }^{\circledR}$ GP-22 ABS granules from BASF Corporation are used as raw materials for manufacturing of plastic plaques [23]. Injection molded natural polycarbonate and opaque ABS plaques of dimensions $80 \times 35 \times 4 \mathrm{~mm}$ of each are used as the work materials. Natural polycarbonate is transparent to the laser radiation (Transmissibility is about $92 \%$ of incident laser radiation at the wavelength of diode lasers). ABS

Table 1 Process control parameters and their limits

\begin{tabular}{|c|c|c|c|c|c|c|c|}
\hline \multirow[t]{2}{*}{ Parameters } & \multirow[t]{2}{*}{ Units } & \multirow[t]{2}{*}{ Notations } & \multicolumn{5}{|c|}{ Limits } \\
\hline & & & -2 & -1 & 0 & +1 & +2 \\
\hline Laser power & Watt & $P$ & 8 & 11 & 14 & 17 & 20 \\
\hline Welding speed & $\mathrm{mm} / \mathrm{s}$ & $S$ & 4 & 7 & 10 & 13 & 16 \\
\hline Stand-off-distance & $\mathrm{mm}$ & $F$ & 25 & 30 & 35 & 40 & 45 \\
\hline Clamp pressure & $\mathrm{MPa}$ & $C$ & 0.9 & 1.8 & 2.7 & 3.6 & 4.5 \\
\hline
\end{tabular}


plaques are rendered laser absorbing by adding $0.1 \%$ weight carbon black pigments in the polymer matrix.

In the present research, welding experiments are performed with a continuously emitting diode laser system. The photographic view of the experimental set up for present work is shown in Fig. 1. The system installation consists of a $30 \mathrm{~W}$ Coherent FAP diode laser with a 3-axes CNC work table, coordinated with the motion system and computer interface. The diode laser is operated at $809.4 \mathrm{~nm}$ wavelength and the focal length used is $13 \mathrm{~mm}$. The FAP system optical radiation is delivered via SMA 905 connector, which mates to an $800 \mu \mathrm{m}$ diameter transport fiber. A welding fixture is used for repeating work, to maintain the lapping area constant i.e., $20 \times 35 \mathrm{~mm}$, for every run and to prevent misalignment between the parts to be welded in lap joint geometry. The work materials are placed on the metal plate of the holding fixture with the polycarbonate sample on top, with an overlap between the polycarbonate and ABS plaques of approximately $20 \mathrm{~mm}$. The laser, at a set stand-off distance, scan across the width of the overlapped samples, centered at a distance of about $10 \mathrm{~mm}$ from the end of the overlapped area. Hydraulic clamp pressure is applied in between the workpieces to ensure the intimate contact between them. The pressure applied to the workpieces is determined from the reading of the pressure gauge, fitted to the hydraulic pump, converted to the pressure experienced by the plaques based on the actual area of contact between the overlapped sections of each sample. The contour welding variant of laser transmission welding is adopted for this study. Figure 2 shows a weld sample in lap joint configuration.

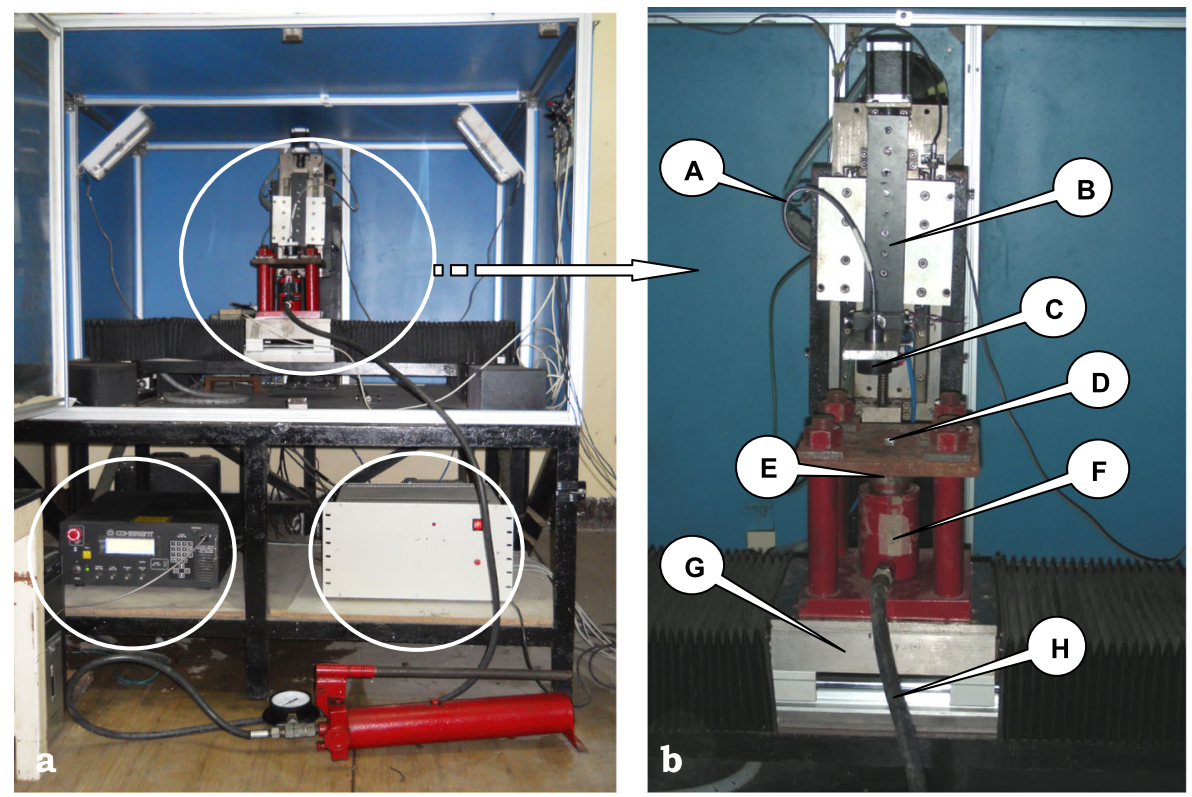

Fig. 1 Photograph of (a) Experimental setup, and (b) laser delivery system with work station (where, $\mathrm{A}=$ Fiber optic transport cable, $\mathrm{B}=\mathrm{CNC}$ z-axis motor driven carriage, $\mathrm{C}=$ Laser optics, $\mathrm{D}=$ Slot for passing laser, $\mathrm{E}=$ welding fixture, $\mathrm{F}=$ Clamp pressure system, $\mathrm{G}=\mathrm{CNC} \mathrm{x}-\mathrm{y}$ table, $\mathrm{H}=$ Hose connected with hydraulic pump) 


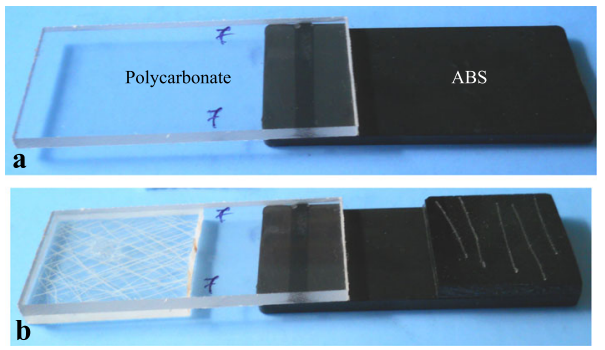

Fig. 2 Pictorial view of (a) welded sample in lap joint configuration, and (b) the sample used for lap-shear test

Polycarbonate and ABS, both, as amorphous polymers, do not have any sharp melting point. They start to soften at their respective glass transition temperatures. At that temperature they act like mushy rubber and a weld can be formed above this temperature. Polycarbonate has a higher glass transition temperature $\left(145-150{ }^{\circ} \mathrm{C}\right)$ than ABS $\left(106-110^{\circ} \mathrm{C}\right)$. Because of the difference between their glass transition temperatures, the melt width for both the parts at weld interface is not same. The weld seam visible through the transparent polycarbonate part, in Fig. 3a, is actually the melt width in ABS part. Figure $3 b$ is a temperature contour plot of weld zone cross-section (half of the model from symmetry line) [23], which is drawn using commercial finite element software ANSYS ${ }^{\circledR}$. It is evident from this figure that the melt width in polycarbonate part is lesser than that of ABS due to the higher glass transition temperature of polycarbonate. A term 'track width' [2] is generally used in preference to weld seam width for describing weld seam in laser transmission welding of dissimilar plastics, which is illustrated clearly in Fig. 3c. It can be seen from Fig. $3 b$ that both the materials are melted or softened at the zone above $150{ }^{\circ} \mathrm{C}$, because the glass transition temperature of both the plastics are either equal to or less than $150{ }^{\circ} \mathrm{C}$. A fusion bonding is likely to be took place between them at this zone. However, only $\mathrm{ABS}$ is melted or softened at the zone between 110 and $150{ }^{\circ} \mathrm{C}$. In this region, a bonding similar to adhesive bonding between them is expected, as polycarbonate does not melt at this temperature zone. In this study, the term 'track width' is used to describe the weld seam width. The track width for each specimen is measured using an optical measuring microscope (Olympus STM6). At least three measurements of track width are taken at different positions along the weld line and average of theses is taken for further analysis. The strength of the weld is measured with tensile strength test using a microprocessor-controlled $100 \mathrm{kN}$ Instron universal tester with an accuracy of $\pm 0.4 \%$ of the rated capacity. The crosshead speed during the shear test is kept constant at $0.5 \mathrm{~mm} /$ min. Before pulling, the samples are marked about $30 \mathrm{~mm}$ from the weld centerline, and the ends of the grips are aligned with these marks. Some adjustments are made to the specimens to be shear tested. To minimize the bending moments at the weldline during the tests, two plastic plaques of dimensions $40 \times 35 \times 4 \mathrm{~mm}$ are pasted with each specimen, as shown in the Fig. $2 \mathrm{~b}$, so that the weld is close to the centerline of the pulling direction. After that, each specimen is roughened at both sides of two ends to prevent slip during lap-shear test. The weld strength is calculated as the maximum load to failure per unit 


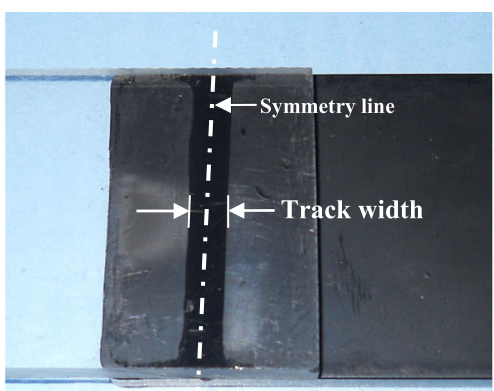

a
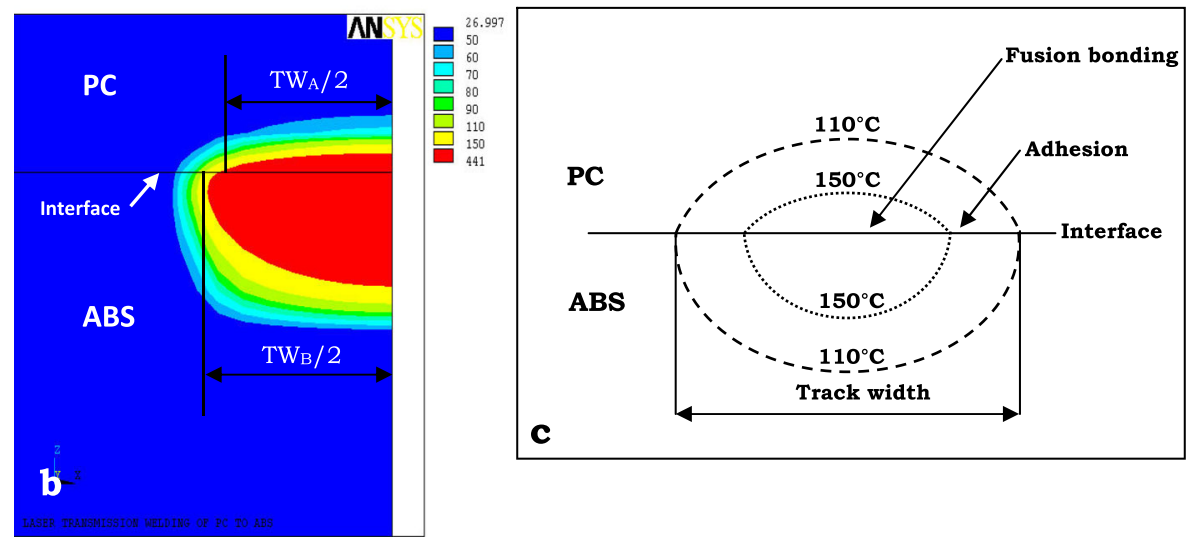

Fig. 3 (a) top view of track width through the transparent polycarbonate part, (b) melt half width ${ }^{*}$ for both the parts at weld interface, and (c) cross-sectional scheme of track width ${ }^{*}\left(\mathrm{TW}_{\mathrm{A}} / 2=\right.$ melt half width in top transparent part, and $\mathrm{TW}_{\mathrm{B}} / 2$ = melt half width in bottom opaque part, i.e., half of the track width, which is visible through the transparent top part)

length of the weld in $\mathrm{N} / \mathrm{mm}$. The average of at least three results of both weld strength and track width are calculated and presented in Table 2. It is seen from Table 2 that the maximum weld strength achieved is $38.86 \mathrm{~N} / \mathrm{mm}$ which corresponds to the track width of $5.16 \mathrm{~mm}$, next to the maximum value. Apparently, the weld strength in terms of force per unit area of weld is $7.53 \mathrm{~N} / \mathrm{mm}^{2}$. However, the effective weld area (unit length of weld $\times$ melt width of PC) which is actually resisting the pulling load is much lower than the weld area (unit length of weld $\times$ track width) used for the above calculation. Thus, the weld strength in terms of force per unit area of weld is obviously higher than that of the calculated value. That is why the weld strength is normalized by the length of the weld (i.e., $\mathrm{N} / \mathrm{mm}$ ) instead of the area of the weld (i.e., $\mathrm{N} / \mathrm{mm}^{2}$ ). The weld strength achieved for the PC to ABS dissimilar plastic welding, in present work, is lower than that for the combination of PC to PC [24] and ABS to ABS [25] similar plastic welding, using laser transmission welding process. The highest weld strength achieved for PC to ABS welded part $(38.86 \mathrm{~N} / \mathrm{mm})$ is 19 and $24 \%$ of the bulk material, for PC and ABS, respectively, which is dependent on the process parameters. 
Table 2 Design matrix and measured experimental results

\begin{tabular}{|c|c|c|c|c|c|c|c|c|}
\hline \multirow[t]{3}{*}{ Exp. no. } & \multicolumn{4}{|c|}{ Welding parameter level } & \multicolumn{4}{|c|}{ Measured output } \\
\hline & \multirow[t]{2}{*}{$P(\mathrm{~W})$} & \multirow[t]{2}{*}{$S(\mathrm{~mm} / \mathrm{s})$} & \multirow[t]{2}{*}{$F(\mathrm{~mm})$} & \multirow[t]{2}{*}{$C(\mathrm{MPa})$} & \multicolumn{2}{|c|}{ Weld strength $(\mathrm{N} / \mathrm{mm})$} & \multicolumn{2}{|c|}{ Track width (mm) } \\
\hline & & & & & Mean & Standard deviation & Mean & Standard deviation \\
\hline 1 & -1 & -1 & -1 & -1 & 8.34 & \pm 0.37 & 2.99 & \pm 0.003 \\
\hline 2 & 1 & -1 & -1 & -1 & 11.83 & \pm 0.23 & 3.46 & \pm 0.003 \\
\hline 3 & -1 & 1 & -1 & -1 & 19.54 & \pm 0.72 & 2.71 & \pm 0.005 \\
\hline 4 & 1 & 1 & -1 & -1 & 21.94 & \pm 0.44 & 3.13 & \pm 0.004 \\
\hline 5 & -1 & -1 & 1 & -1 & 16.63 & \pm 0.46 & 4.41 & \pm 0.006 \\
\hline 6 & 1 & -1 & 1 & -1 & 28.97 & \pm 0.53 & 4.99 & \pm 0.003 \\
\hline 7 & -1 & 1 & 1 & -1 & 11.66 & \pm 0.26 & 3.79 & \pm 0.005 \\
\hline 8 & 1 & 1 & 1 & -1 & 21.89 & \pm 0.31 & 4.52 & \pm 0.003 \\
\hline 9 & -1 & -1 & -1 & 1 & 15.03 & \pm 0.22 & 2.98 & \pm 0.002 \\
\hline 10 & 1 & -1 & -1 & 1 & 17.71 & \pm 0.32 & 3.58 & \pm 0.003 \\
\hline 11 & -1 & 1 & -1 & 1 & 14.69 & \pm 0.54 & 2.74 & \pm 0.005 \\
\hline 12 & 1 & 1 & -1 & 1 & 16.91 & \pm 0.47 & 3.21 & \pm 0.004 \\
\hline 13 & -1 & -1 & 1 & 1 & 23.51 & \pm 0.36 & 4.58 & \pm 0.006 \\
\hline 14 & 1 & -1 & 1 & 1 & 38.86 & \pm 0.42 & 5.16 & \pm 0.004 \\
\hline 15 & -1 & 1 & 1 & 1 & 12.17 & \pm 0.32 & 3.76 & \pm 0.003 \\
\hline 16 & 1 & 1 & 1 & 1 & 16.74 & \pm 0.35 & 4.53 & \pm 0.005 \\
\hline 17 & -2 & 0 & 0 & 0 & 9.03 & \pm 0.74 & 3.06 & \pm 0.005 \\
\hline 18 & 2 & 0 & 0 & 0 & 21.77 & \pm 0.34 & 4.23 & \pm 0.004 \\
\hline 19 & 0 & -2 & 0 & 0 & 15.66 & \pm 0.49 & 4.21 & \pm 0.007 \\
\hline 20 & 0 & 2 & 0 & 0 & 13.49 & \pm 0.24 & 3.52 & \pm 0.004 \\
\hline 21 & 0 & 0 & -2 & 0 & 9.31 & \pm 0.87 & 2.55 & \pm 0.008 \\
\hline 22 & 0 & 0 & 2 & 0 & 24.06 & \pm 0.72 & 5.45 & \pm 0.009 \\
\hline 23 & 0 & 0 & 0 & -2 & 29.43 & \pm 0.25 & 3.79 & \pm 0.005 \\
\hline 24 & 0 & 0 & 0 & 2 & 28.81 & \pm 0.32 & 3.96 & \pm 0.003 \\
\hline 25 & 0 & 0 & 0 & 0 & 31.03 & \pm 0.12 & 3.82 & \pm 0.002 \\
\hline 26 & 0 & 0 & 0 & 0 & 33.14 & \pm 0.33 & 3.81 & \pm 0.003 \\
\hline 27 & 0 & 0 & 0 & 0 & 32.22 & \pm 0.28 & 3.82 & \pm 0.004 \\
\hline 28 & 0 & 0 & 0 & 0 & 30.06 & \pm 0.22 & 3.73 & \pm 0.002 \\
\hline 29 & 0 & 0 & 0 & 0 & 32.71 & \pm 0.19 & 3.85 & \pm 0.003 \\
\hline 30 & 0 & 0 & 0 & 0 & 31.71 & \pm 0.26 & 3.87 & \pm 0.005 \\
\hline
\end{tabular}

\section{Development of Empirical Models}

Response surface methodology is employed to develop the empirical models, which can be used to predict the weld strength and track width. The adequacy of the model is tested using the sequential $F$-test, lack-of-fit test and the analysis-of-variance technique (ANOVA) to obtain the best-fit models. 
Analysis of Weld Strength

The fit summary for weld strength suggests the quadratic model where the additional terms are significant and the model is not aliased. The ANOVA table of the quadratic model with other adequacy measures $R^{2}$, adjusted $R^{2}$ and predicted $R^{2}$ are given in Table 3 . The analysis-of-variance result shows that the main effect of the laser power $(P)$, welding speed $(S)$, stand-off-distance $(F)$, the quadratic effect of the laser power $\left(P^{2}\right)$, welding speed $\left(S^{2}\right)$, stand-offdistance $\left(F^{2}\right)$, clamp pressure $\left(C^{2}\right)$, along with the interaction effect of the laser power and welding speed $(P \times S)$, laser power and stand-off-distance $(P \times F)$, welding speed and stand-off-distance $(S \times F)$, welding speed and clamp pressure $(S \times C)$, are the significant model terms associated with weld strength. The other model terms are not significant and thus, eliminated by backward elimination process to improve model adequacy. Nevertheless, the main effect of clamp pressure $(C)$ is added to support hierarchy. The associated $p$-value (probability value) of less than 0.05 for the model (i.e., $\alpha=0.05$, or $95 \%$ confidence level) indicates that the model terms are statistically significant. The other adequacy measures $R^{2}$, adjusted $R^{2}$ and predicted $R^{2}$ are in reasonable

Table 3 ANOVA analysis for the weld strength model

\begin{tabular}{lcclcr}
\hline Source & Sum of squares & D.o.f & Mean squares & $F$-value & $p$-value \\
\hline Model & 2106.44 & 12 & 175.54 & 62.13 & $<0.0001$ \\
$P$ & 258.46 & 1 & 258.46 & 91.48 & $<0.0001$ \\
$S$ & 36.70 & 1 & 36.70 & 12.99 & 0.0022 \\
$F$ & 227.80 & 1 & 227.80 & 80.63 & $<0.0001$ \\
$C$ & 7.68 & 1 & 7.68 & 2.72 & 0.1175 \\
$P S$ & 13.03 & 1 & 13.03 & 4.61 & 0.0464 \\
$P F$ & 62.81 & 1 & 62.81 & 22.23 & 0.0002 \\
$P C$ & $*$ & $*$ & $*$ & $*$ & $*$ \\
$S F$ & 269.62 & 1 & 269.62 & 95.43 & $<0.0001$ \\
$S C$ & 120.23 & 1 & 120.23 & 42.56 & $<0.0001$ \\
$F C$ & $*$ & $*$ & $*$ & $*$ & $*$ \\
$P^{2}$ & 477.57 & 1 & 477.57 & 169.04 & $<0.0001$ \\
$S^{2}$ & 525.95 & 1 & 525.95 & 186.16 & $<0.0001$ \\
$F^{2}$ & 406.87 & 1 & 406.87 & 144.01 & $<0.0001$ \\
$C^{2}$ & 15.13 & 1 & 15.13 & 5.36 & 0.0334 \\
Residual & 48.03 & 17 & 2.83 & & \\
Lack of Fit & 41.60 & 12 & 3.47 & 2.70 & 0.1409 \\
Pure Error & 6.43 & 5 & 1.29 & & \\
Total & 2154.47 & 29 & & & \\
$R^{2}=0.9777$ & & & Adjusted $R^{2}=0.9620$ & & \\
Predicted $R^{2}=0.9172$ & & & Adequate Precision & 26.53 & \\
\hline & & & & & \\
\end{tabular}

*Term eliminated from model (Backward elimination regression with alpha to exit $=0.100$ ) 
agreement and are close to 1, which indicate adequacy of the model. The adequate precision compares the signal to noise ratio and a ratio greater than 4 is desirable. The value of adequate precision ratio of 26.53 indicates adequate model discrimination. The lack-of-fit $F$-value of 2.70 implies that the lack-of-fit is not significant relative to the pure error.

The final empirical models for weld strength $\left(Y_{w s}\right)$, which can be used for prediction within same design space, are given as follows:

(a) In terms of coded factors,

$$
\begin{aligned}
Y_{w s}= & 31.81+3.28 P-1.24 S+3.08 F+0.57 C+0.90 P S \\
& +1.98 P F-4.11 S F-2.74 S C-4.17 P^{2}-4.38 S^{2}-3.85 F^{2}-0.74 C^{2}
\end{aligned}
$$

(b) In terms of actual factors,

$$
\begin{aligned}
Y_{w s}= & -410.091+10.456 P+23.042 S+12.288 F+15.733 C-0.100 P S \\
& +0.132 P F-0.274 S F-1.015 S C-0.464 P^{2}-0.487 S^{2}-0.154 F^{2}-0.917 C^{2}
\end{aligned}
$$

Analysis of Track Width

For track width, the fit summary recommends the quadratic model where the additional terms are significant and the model is not aliased. Table 4 presents the ANOVA table of the quadratic model with other adequacy measures $R^{2}$, adjusted $R^{2}$ and predicted $R^{2}$. The ANOVA result shows that the main effect of the laser power $(P)$, welding speed $(S)$, stand-off-distance $(F)$, clamp pressure $(C)$, the quadratic effect of the laser power $\left(P^{2}\right)$, stand-off-distance $\left(F^{2}\right)$, along with the interaction effect of the laser power and stand-off-distance $(P \times F)$, welding speed and stand-off-distance $(S \times F)$, are the significant model terms associated with track width. The other model terms are not significant and thus, eliminated by backward elimination process to improve model adequacy. The reduced model results indicate that the model is significant ( $p$-value less than 0.05). The other adequacy measures $R^{2}$, adjusted $R^{2}$ and predicted $R^{2}$ are in reasonable agreement and are close to 1 , which indicate adequate model. The value of adequate precision ratio 72.44 indicates adequate model discrimination. The lack-of-fit $F$-value of 2.50 implies that the lack-of-fit is not significant relative to the pure error.

The final empirical models for track width $\left(Y_{t w}\right)$, as determined by Design Expert ${ }^{\circledR}$ software are given as follows:

(a) In terms of coded factors,

$$
\begin{aligned}
Y_{t w}= & 3.820+0.290 P-0.210 S+0.700 F+0.037 C \\
& +0.044 P F-0.082 S F-0.054 P^{2}+0.035 F^{2}
\end{aligned}
$$


Table 4 ANOVA analysis for the track width model

\begin{tabular}{|c|c|c|c|c|c|}
\hline Source & Sum of squares & D.o.f & Mean squares & $F$-value & $p$-value \\
\hline Model & 15.0980 & 8 & 1.8872 & 381.6601 & $<0.0001$ \\
\hline$P$ & 2.0184 & 1 & 2.0184 & 408.1830 & $<0.0001$ \\
\hline$S$ & 1.1008 & 1 & 1.1008 & 222.6192 & $<0.0001$ \\
\hline$F$ & 11.6762 & 1 & 11.6762 & 2361.2790 & $<0.0001$ \\
\hline$C$ & 0.0323 & 1 & 0.0323 & 6.5253 & 0.0185 \\
\hline$P S$ & $*$ & $*$ & $*$ & $*$ & $*$ \\
\hline$P F$ & 0.0306 & 1 & 0.0306 & 6.1933 & 0.0213 \\
\hline$P C$ & $*$ & $*$ & $*$ & $*$ & $*$ \\
\hline$S F$ & 0.1089 & 1 & 0.1089 & 22.0230 & 0.0001 \\
\hline$S C$ & $*$ & $*$ & $*$ & $*$ & * \\
\hline$F C$ & $*$ & $*$ & $*$ & * & * \\
\hline$P^{2}$ & 0.0831 & 1 & 0.0831 & 16.8127 & 0.0005 \\
\hline$S^{2}$ & $*$ & $*$ & $*$ & $*$ & * \\
\hline$F^{2}$ & 0.0342 & 1 & 0.0342 & 6.9214 & 0.0156 \\
\hline$C^{2}$ & $*$ & $*$ & $*$ & $*$ & $*$ \\
\hline Residual & 0.1038 & 21 & 0.0049 & & \\
\hline Lack of Fit & 0.0923 & 16 & 0.0058 & 2.5011 & 0.1582 \\
\hline Pure Error & 0.0115 & 5 & 0.0023 & & \\
\hline Total & 15.2018 & 29 & & & \\
\hline \multicolumn{3}{|l|}{$R^{2}=0.9932$} & \multicolumn{3}{|c|}{ Adjusted $R^{2}=0.9906$} \\
\hline \multicolumn{3}{|c|}{ Predicted $R^{2}=0.9839$} & \multicolumn{3}{|c|}{ Adequate Precision $=72.44$} \\
\hline
\end{tabular}

*Term eliminated from model (Backward elimination regression with alpha to exit $=0.100$ )

(b) In terms of actual factors,

$$
\begin{aligned}
Y_{t w}=- & 1.7830+0.1628 P+0.1211 S+0.0565 F+0.0407 C \\
& +2.9166 \mathrm{E}-03 P F-5.5000 \mathrm{E}-03 S F-6.0069 \mathrm{E}-03 P^{2}+1.3875 \mathrm{E}-03 F^{2}
\end{aligned}
$$

Validation of the Developed Models

Three confirmation experiments are conducted to validate the developed response surface equations. Welding conditions are chosen randomly within the ranges for which the equations are derived. It is observed from Table 5 that there is a small error percentage between the estimated and the experimental values, which indicate that the developed models can predict the output results with significant accuracy. Figure $4 \mathrm{a} \& \mathrm{~b}$ show the relationship between the actual and predicted values of weld strength and track width, respectively. These figures indicate that the developed models are adequate and predicted results are in good agreement with measured data. 
Table 5 Validation test results

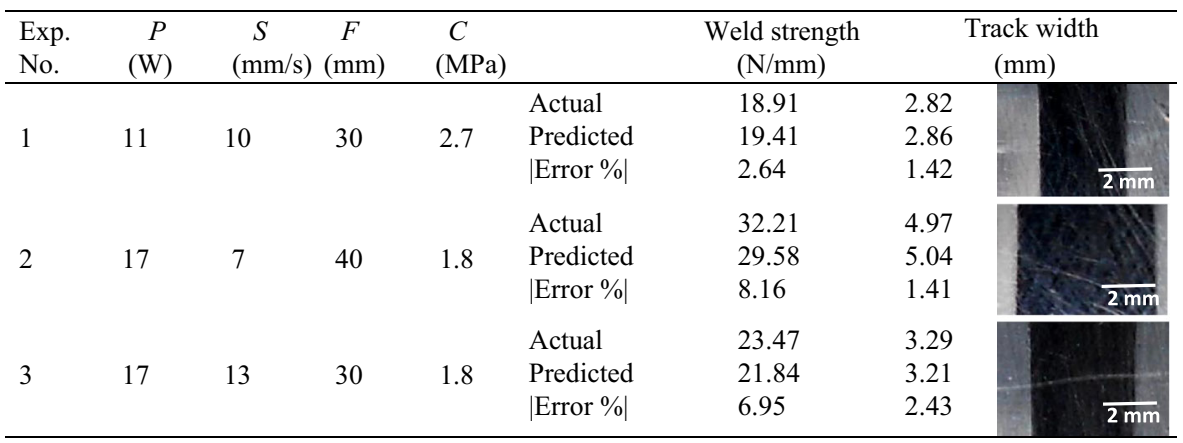

\section{Effects of Process Parameters on Responses}

\section{Weld Strength}

The results indicate that the laser power and stand-off distance are the most important factors affecting the weld strength. Welding speed also contributes significantly to the weld strength. Figure 5 is a perturbation plot, which illustrates the effect of all the factors at the center point in the design space. It is seen from Fig. 5, that weld strength increases with laser power upto a threshold value and thereafter it starts decreasing. This threshold value of input laser power is related to the decomposition temperature of the base material. This implies that increasing the laser power increases the weld strength until the critical temperature of decomposition is reached. It is also evident from this figure that increasing the welding speed, upto its center value, increases the weld strength. A further increase of the welding speed decreases the weld strength. A slower welding speed results in higher line energy (i.e., the ratio of laser power and welding speed, defined as the input energy per unit length) that may cause partial degradation and burning of the material, consequently less weld strength is achieved. Weld strength increases with the welding speed upto $10 \mathrm{~mm} / \mathrm{s}$. Thereafter the weld strength decreases with the increase of welding speed. This is because of reduction in line energy, which is required for proper fusion and penetration. Same trend is observed for stand-off distance. Varying the stand-off distance varies the laser beam diameter on workpiece, and thus controls the power density. The weld strength is restricted at very high power density, which causes material decomposition and a very low power density results in lack of fusion. Clamp pressure has statistically insignificant effect on weld strength. Clamp pressure improves thermal contact conduction between the mating parts, thus improves the weld strength. However, at higher levels of clamp pressure, weld strength is slightly reduced because of melt ejection from the two ends of the weld seam. Figure 6 shows the interaction effects of the (a) laser power and welding speed, (b) laser power and stand-off-distance, (c) welding speed and stand-off-distance, and (d) welding speed and clamp pressure on weld strength, while the remaining parameters are at their respective center values. These plots are graphic representation of the relationships among three numeric variables in two dimensions which correspond to weld strength as a function of two independent variables. 

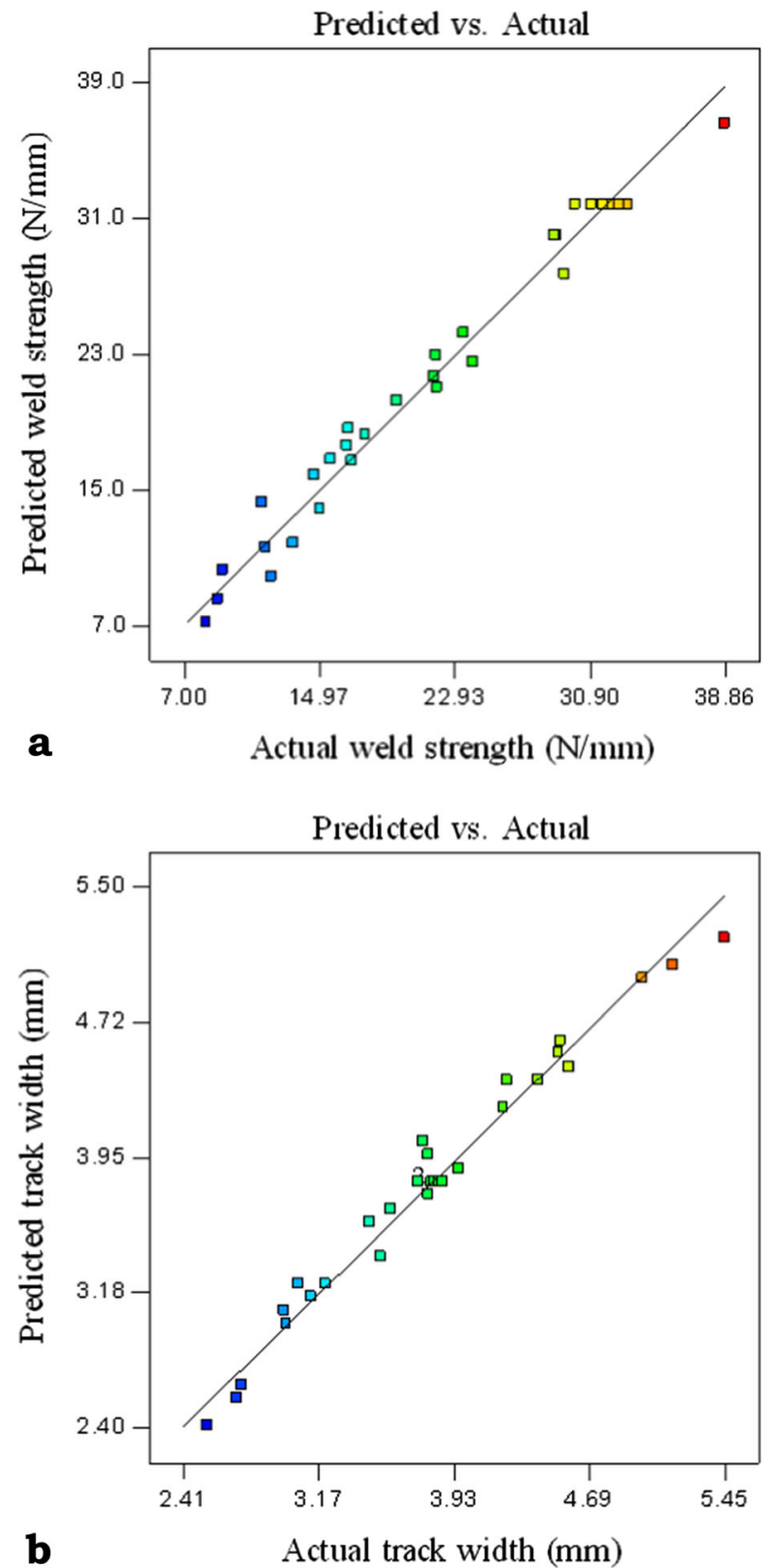

Fig. 4 Plot of actual vs. predicted response of (a) weld strength results \& (b) track width results

Track Width

The results indicate that the stand-off distance is the most important factor affecting the track width, and it is followed by laser power, welding speed and clamping pressure. It is evident from Fig. 7 that track width increases with laser power. This is because of the fact that greater volume of base material is melted with increased laser power, and 


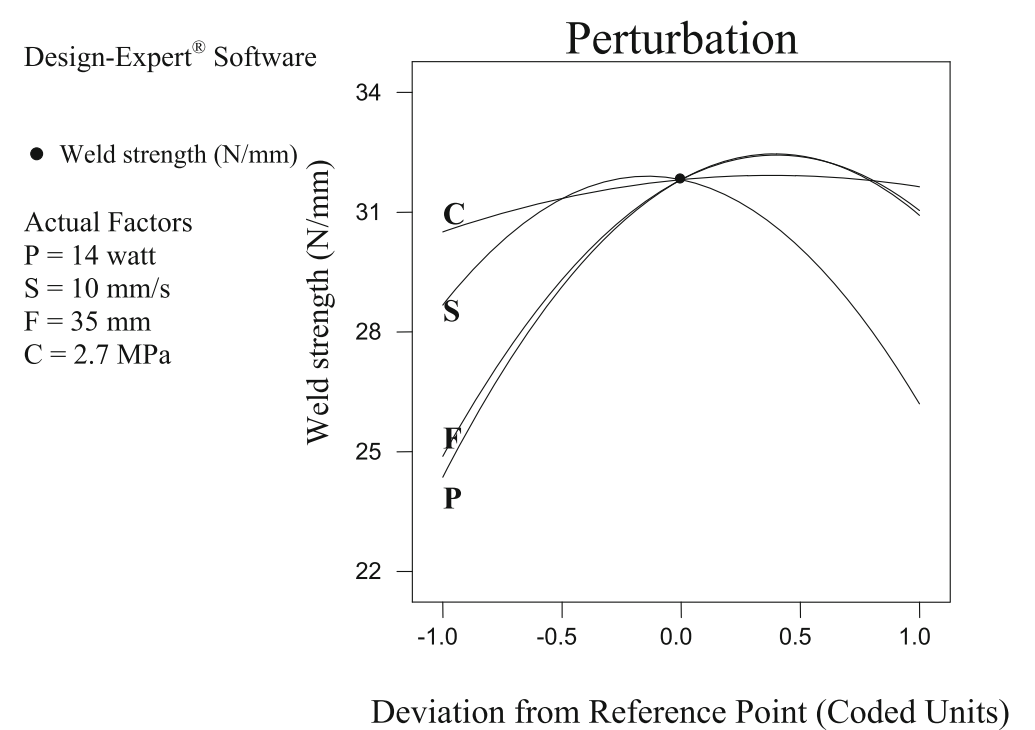

Fig. 5 Perturbation plot showing the effect of all factors on the weld strength

consequently the width of the weld zone increases. An increase in welding speed leads to a decrease in track width. The line energy decreases as the welding speed increases, and less heat is delivered to the weld zone. This leads to a narrower track width. It is seen from the same figure that the track width increases with stand-off distance. Increasing stand-off distance results in spreading the laser energy onto a wide area thus forms a wider track width. It is also observed that clamp pressure contributes slightly positively to track width. Figure 8 is the contour plots showing the interaction effects of the (a) laser power and stand-off-distance, and (b) welding speed and standoff-distance on track width, while the remaining parameters are at their respective center values.

\section{Optimization}

Numerical Optimization

The optimization module in Design Expert ${ }^{\circledR}$ searches for a combination of factor levels that simultaneously satisfy the requirements placed on each of the responses and factors. Numerical optimization searches the design space, using the developed regression model to find the factor settings that optimize any combination of one or more goals. The goals are combined into an overall desirability function. The numerical optimization finds a point that maximizes this desirability function.

Two optimization criteria are implemented in the present numerical optimization scheme. In the first criterion, the goals are set to maximize the weld strength and to minimize the track width; whereas, the process parameters are kept within the range of studied design space. The second criterion is set to a 


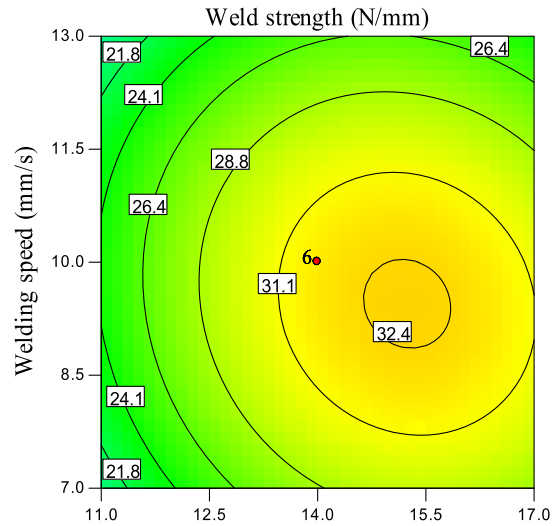

a

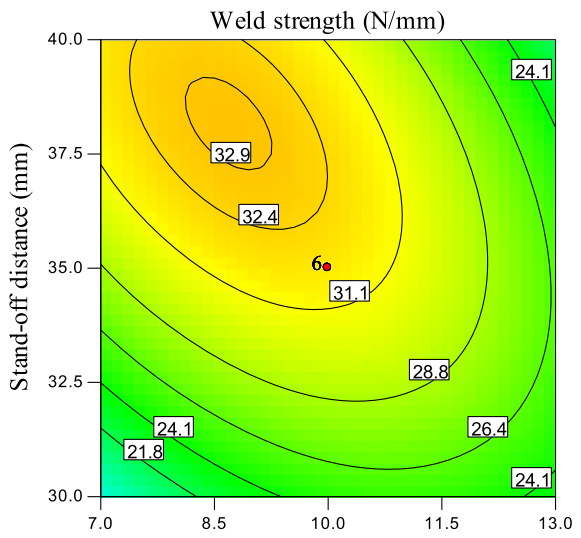

Welding speed $(\mathrm{mm} / \mathrm{s})$

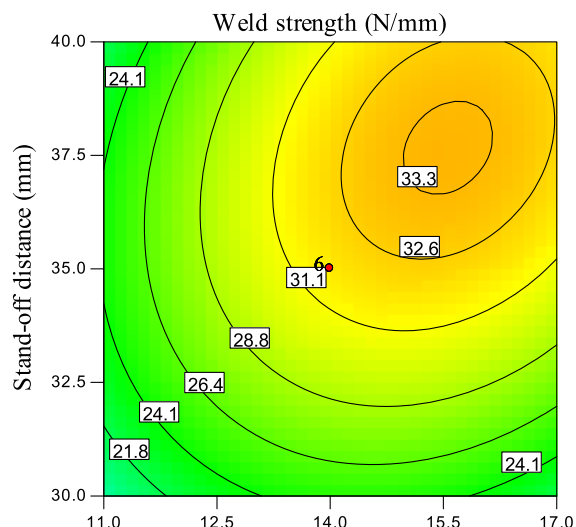

b

Laser Power (W)

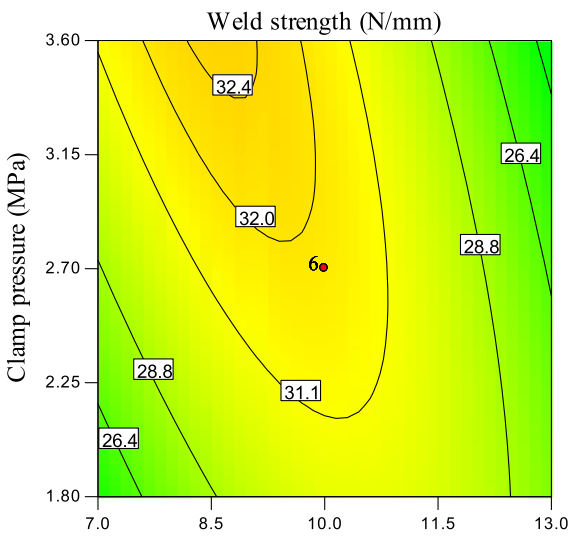

Welding speed $(\mathrm{mm} / \mathrm{s})$

Fig. 6 Contour plots showing the interaction effects of the (a) laser power and welding speed $(P \times S)$, (b) laser power and stand-off-distance $(P \times F)$, (c) welding speed and stand-off-distance $(S \times F)$, and $($ d) welding speed and clamp pressure $(S \times C)$ on weld strength, while the remaining parameters are at their respective center values

target of $3 \mathrm{~mm}$ track width and to maximize the weld strength by minimizing the laser power requirement and maximizing the process throughput while rest of the process parameters are kept within the range of the studied factor domain. Table 6 illustrates these two criteria, representing the goals, upper and lower limits, as well as the importance of each goal for each response and factor in the first and second criterion, respectively.

Table 7 furnishes the best five set of pareto optimal parameter combinations for each of the selected criteria. According to the first criterion, the optimum parametric range for the laser power has to be 13.66-13.67 W, welding speeds has to be $11.95-11.96 \mathrm{~mm} / \mathrm{s}$ and stand-off-distance within the range of 31.79 $31.81 \mathrm{~mm}$ using a clamping pressure of $1.76-1.77 \mathrm{MPa}$, which leads to achieve a maximum weld strength of $27.56 \mathrm{~N} / \mathrm{mm}$ along with minimum track width of 


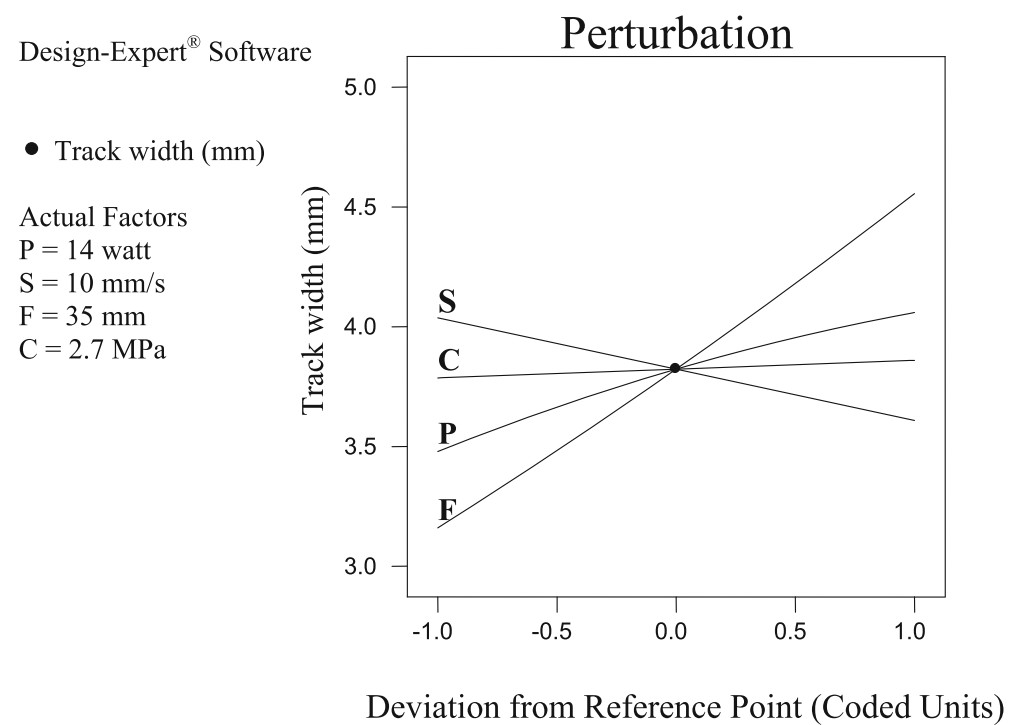

Fig. 7 Perturbation plot showing the effect of all factors on the track width

$3.216 \mathrm{~mm}$. It is evident from the results of second criterion that to achieve a $3 \mathrm{~mm}$ wide weld seam with maximum possible lap-shear strength, the minimum working range for laser power has to be 12.54-12.56 W, and the maximum working range for welding speed has to be $13.64-13.65 \mathrm{~mm} / \mathrm{s}$, where as the stand-off-distance within the range of 31.95-31.96 mm for the clamp pressure varying from 0.94 to $0.96 \mathrm{MPa}$. For both the criteria, the parameter combinations with highest desirability values are selected as the best laser transmission welding conditions, accordingly.

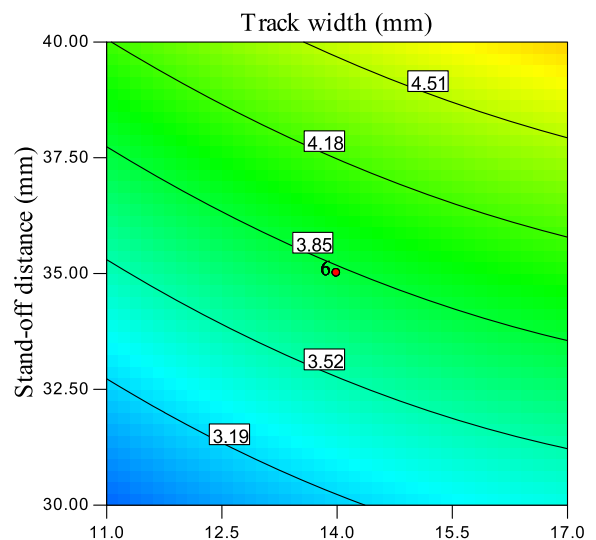

$\mathbf{a}$

Laser Power (W)

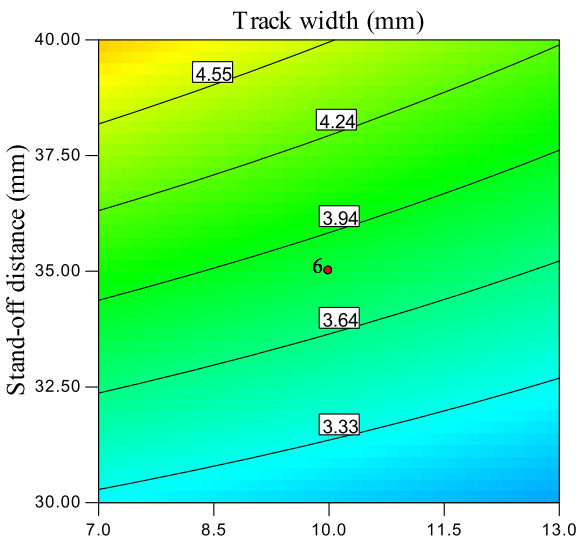

b

Fig. 8 Contour plots showing the interaction effects of the (a) laser power and stand-off-distance $(P \times F)$, and (b) welding speed and stand-off-distance $(S \times F)$ on track width, while the remaining parameters are at their respective center values 
Table 6 The selected criteria for numerical optimization

\begin{tabular}{lccllll}
\hline Parameter or response & \multicolumn{2}{l}{ Limit } & & & Goals & Importance \\
\cline { 2 - 3 } \cline { 5 - 6 } & Lower & Upper & & First criterion & Second criterion & \\
\hline$P, \mathrm{~W}$ & 8 & 20 & & Is in range & Minimize & 3 \\
$S, \mathrm{~mm} / \mathrm{s}$ & 4 & 16 & & Is in range & Maximize & 3 \\
$F, \mathrm{~mm}$ & 25 & 45 & & Is in range & Is in range & 3 \\
$C, \mathrm{MPa}$ & 0.9 & 4.5 & & Is in range & Is in range & 3 \\
Weld strength, N/mm & 8.34 & 38.86 & & Maximize & Maximize & 5 \\
Track width, mm & 2.55 & 5.45 & & Minimize & Is target $=3 \mathrm{~mm}$ & 5 \\
\hline
\end{tabular}

Graphical Optimization

A relatively straight forward approach of optimizing several responses that works well when there are only a few process variables is to overlay the contours plot for each response [19]. By superimposing or overlaying critical response contours on one contour plot, experimenters can visually search for the best compromise. Graphical optimization displays the area of feasible response values in the factor space. Regions that do not fit the optimization criteria are shaded. The response limits, lower and/or upper for each response are included according to the numerical optimization results. The same two criteria, which are used for numerical optimization, are implemented in the graphical optimization.

The graphical optimization results overlay contours plots, which allow quick visual inspection of the area of feasible response values in the factor space to choose the optimum welding parameter combination. In case of dealing with many input variables, it is recommended that numerical optimization be done first, and then graphical optimization; otherwise it could be impossible to uncover a feasible region. The bright areas on the overlay plots in Figs. 9

Table 7 Optimal welding conditions based on the selected criteria

\begin{tabular}{lllllllll}
\hline Criterion & Sol. No. & $P(\mathrm{~W})$ & $S(\mathrm{~mm} / \mathrm{s})$ & $F(\mathrm{~mm})$ & $C(\mathrm{MPa})$ & $\begin{array}{l}\text { Weld strength } \\
(\mathrm{N} / \mathrm{mm})\end{array}$ & $\begin{array}{l}\text { Weld width } \\
(\mathrm{mm})\end{array}$ & Desirability \\
\hline \multirow{2}{*}{ First } & 1 & 13.66 & 11.96 & 31.80 & 1.76 & 27.56 & 3.216 & 0.696 Selected \\
& 2 & 13.66 & 11.96 & 31.79 & 1.77 & 27.55 & 3.215 & 0.696 \\
& 3 & 13.66 & 11.95 & 31.80 & 1.77 & 27.57 & 3.217 & 0.696 \\
& 4 & 13.67 & 11.96 & 31.81 & 1.77 & 27.57 & 3.218 & 0.696 \\
& 5 & 13.67 & 11.95 & 31.81 & 1.77 & 27.59 & 3.220 & 0.696 \\
\multirow{3}{*}{ Second } & 1 & 12.54 & 13.64 & 31.96 & 0.95 & 24.69 & 3.000 & 0.722 Selected \\
& 2 & 12.56 & 13.65 & 31.95 & 0.95 & 24.70 & 3.000 & 0.722 \\
& 3 & 12.55 & 13.64 & 31.95 & 0.96 & 24.70 & 3.000 & 0.722 \\
& 4 & 12.55 & 13.65 & 31.96 & 0.94 & 24.69 & 3.000 & 0.722 \\
& 5 & 12.55 & 13.65 & 31.96 & 0.94 & 24.70 & 3.000 & 0.722
\end{tabular}




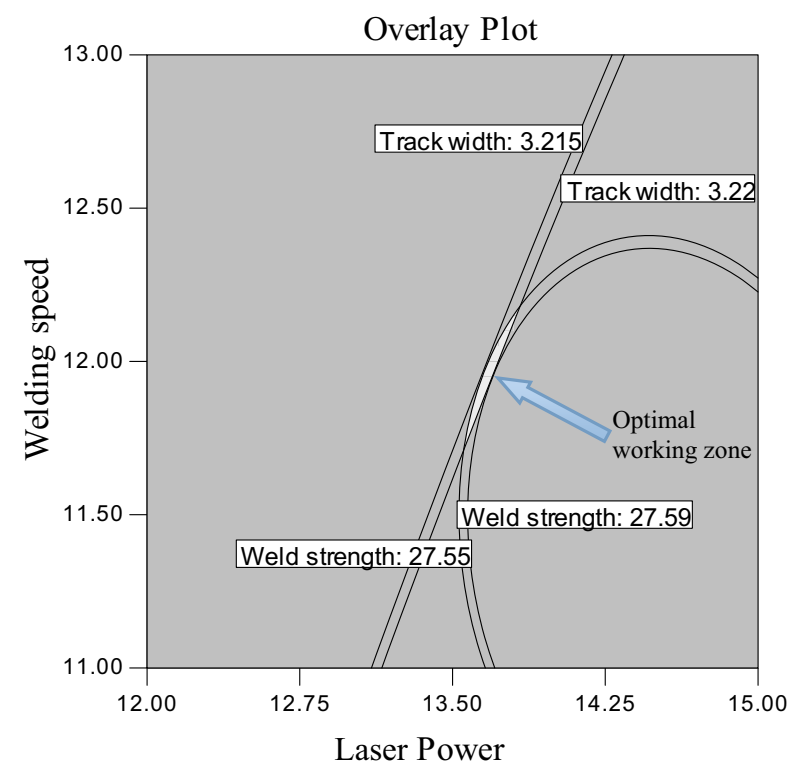

Fig. 9 Overlay plot shows the region of the optimal working condition based on the first criterion at stand-off distance $=31.80 \mathrm{~mm}$ and clamp pressure $=1.76 \mathrm{MPa}$

and 10 indicate the region of interest where all the goals for each response and factor meet. The highlighted area on the overlay contours plot shows the region of optimal working condition, which can also be determined from Table 7 . Region that do not meet the proposed criteria are shaded.

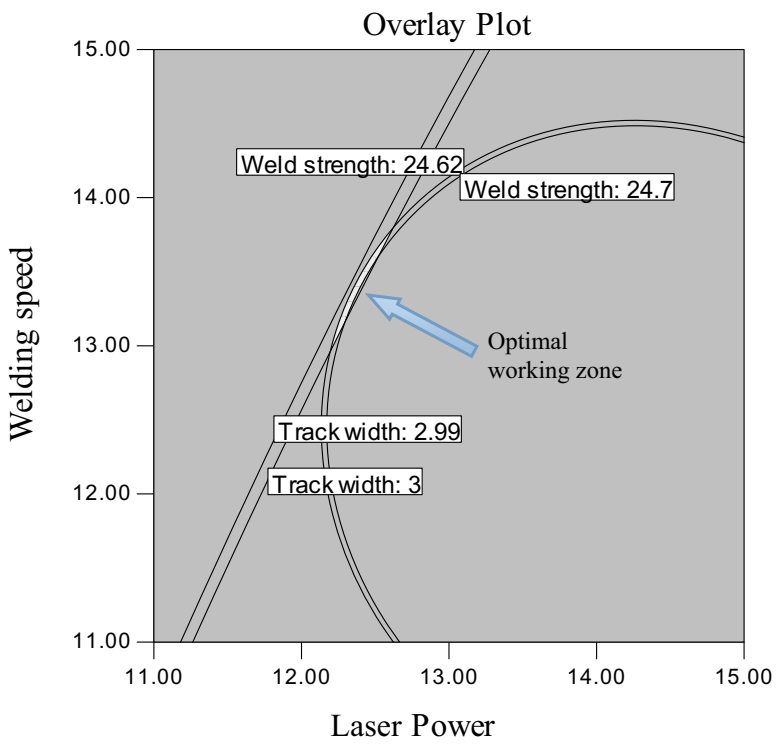

Fig. 10 Overlay plot shows the region of the optimal working condition based on the second criterion at stand-off distance $=31.96 \mathrm{~mm}$ and clamp pressure $=0.95 \mathrm{MPa}$ 


\section{Conclusion}

The following conclusion can be drawn from this investigation within the factors limits considered in this study and for the specified materials combinations:

1. The second order equations developed by RSM using Design Expert ${ }^{\circledR}$ can predict the values of the weld quality characteristics with significant accuracy. The equations are checked for their adequacy with a confidence interval of $95 \%$.

2. Laser power is the most important factors affecting the weld strength, and it is followed by stand-off distance and welding speed. Clamp pressure has statistically insignificant effect on weld strength.

3. Stand-off distance is the most important factor affecting the track width, and it is followed by laser power, welding speed and clamp pressure.

4. Optimal welds could be realized using the welding conditions drawn from the numerical optimization.

5. The graphical optimization results allow quicker search for the optimal welding settings.

\section{References}

1. Kagan, V.A., Pinho, G.P.: Laser transmission welding of semicrystalline thermoplastics - part II: analysis of mechanical performance of welded nylon. J. Reinf. Plast. Compos. 23(1), 95-107 (2004)

2. Baylis, B., Huang, Y.P., Watt, D.: Welding thermoplastic elastomers to polypropylene with a diode laser. Proceedings of the 21st ICALEO, Scottsdale (2002)

3. Haberstroh, E., Luetzeler, R.: Influence of carbon black pigmentation on the laser beam welding of plastics micro parts. J Polymer Eng 21(2-3), 119-129 (2001)

4. Haberstroh E, Luetzeler R. 3D-Laser Transmission Welding. ANTEC (2003)

5. Haberstroh, E., Hoffmann, W.M., Poprawe, R., Sari, F.: 3 laser transmission joining in microtechnology. Microsyst. Technol. 12, 632-639 (2006)

6. Douglass, D.M., Wu, C.Y.: Laser welding of polyolefin elastomers to thermoplastic polyolefin. Proceedings of the 22nd ICALEO, Jacksonville (2003)

7. Grewell, D., Rooney, P., Kagan, V.A.: Relationship between optical properties and optimized processing parameters for through-transmission laser welding of thermoplastics. J. Reinf. Plast. Compos. 23(3), 239247 (2004)

8. Prabhakaran, R., Kontopoulou, M., Zak, G., Bates, P.J., Baylis, B.K.: Contour laser - Laser-transmission welding of glass reinforced nylon 6. J. Thermoplast. Compos. Mater. 19, 427-439 (2006)

9. Wehner, M., Jacobs, P., Poprawe, R.: Rapid prototyping of micro-fluidic components by laser beam processing. Proc. SPIE 6459, 6459081-12 (2007)

10. Ilie, M., Kneip, J.C., Matteï, S., Nichici, A., Roze, C., Girasole, T.: Through-transmission laser welding of polymers - temperature field modeling and infrared investigation. Infrared Phys. Technol. 51(1), 73-79 (2007)

11. Ghorbel, E., Casalino, G., Abed, A.: Laser diode transmission welding of polypropylene: geometrical and microstructure characterization of weld. Mater. Des. 30, 2745-2751 (2008)

12. Speka, M., Matteï, S., Pilloz, M., Ilie, M.: The infrared thermography control of the laser welding of amorphous polymers. NDT\&E Int. 41, 178-183 (2008)

13. Amanat, N., Chaminade, C., Grace, J., McKenzie, D.R., James, N.L.: Transmission laser welding of amorphous and semi-crystalline poly-ether-ether-ketone for applications in the medical device industry. Mater. Des. 31, 4823-4830 (2010) 
14. Acherjee, B., Misra, D., Bose, D., Venkadeshwaran, K.: Prediction of the weld strength and seam width for laser transmission welding of thermoplastics using response surface methodology. Opt. Laser Technol. 41, 956-967 (2009)

15. Acherjee, B., Kuar, A.S., Mitra, S., Misra, D., Acharyya, S.: Experimental investigation on laser transmission welding of dissimilar thermoplastics between PMMA and ABS. Opt. Laser Technol. 44, 1372-1383 (2012)

16. Vidal, E.R., Quintana, I., Etxarri, J., Azkorbebeitia, U., Otaduy, D., González, F., Moreno, F.: Optical design and development of a fiber coupled high-power diode laser system for laser transmission welding of plastics. Opt. Eng. 51(12), 124301 (2012)

17. Vidal, E.R., Quintana, I., Gadea, C.: Laser transmission welding of ABS: effect of CNTs concentration and process parameters on material integrity and weld formation. Opt. Laser Technol. 57, 194-201 (2014)

18. Gunaraj, V., Murugan, N.: Application of response surface methodology for predicting weld bead quality in submerged arc welding of pipes. J. Mater. Process. Technol. 88, 266-275 (1999). doi:10.1016/S09240136(98)00405-1

19. Acherjee, B., Misra, D., Bose, D., Acharyya, S.: Optimal process design for laser transmission welding of acrylics using desirability function analysis and overlay contour plots. Int. J. Manuf. Res. 6(1), 49-61 (2011)

20. Ruggiero, A., Tricarico, L., Olabi, A.G., Benyounis, K.Y.: Weld-bead profile and costs optimisation of the $\mathrm{CO}_{2}$ dissimilar laser welding process of low carbon steel and austenitic steel AISI316. Opt. Laser Technol. 43, 82-90 (2011)

21. Mitra, S., Acherjee, B., Kuar, A.S., Misra, D.: Experimental investigation on diode laser welding of polycarbonate to ABS. MTM Int. Virtual J.: Mach., Tech., Mater. 11, 7-10 (2011)

22. Montgomery, D.C.: Design and analysis of experiments. Wiley, New York (2001)

23. Acherjee, B. Numerical and experimental investigation of laser transmission welding of thermoplastics, $\mathrm{PhD}$ Thesis, Jadavpur University, Kolkata, India, (2011)

24. Russek, U.A.: Laser beam welding of polymers with high power diode lasers - joining innovation for micro and macro technologies. Proceedings of the 20th ICALEO, Jacksonville (2001)

25. Ilie, M., Cicala, E., Grevey, D., Mattei, S., Stoica, V.: Diode laser welding of ABS: experiments and process modeling. Opt. Laser Technol. 41(5), 608-614 (2009) 